\title{
The hip radiographic magnification correlates with patient's BMI
}

\section{Jana Hornová}

Czech technical University in Prague: Ceske Vysoke Uceni Technicke v Praze

\section{Maroš Hrubina}

Comenius University in Bratislava: Univerzita Komenskeho v Bratislave

\section{Eduard Štastný}

University Hospital Motol: Fakultni nemocnice v Motole

\section{Andrea Košková}

Hospital Jablonec nad Nisou

\section{Petr Fulín}

Charles University: Univerzita Karlova

Jiř̌ Gallo

Palacky University Olomouc: Univerzita Palackeho v Olomouci

\section{David Pokorný}

Charles University: Univerzita Karlova

Matej Daniel ( $\sim$ matej.daniel@cvut.cz)

Czech Technical University in Prague https://orcid.org/0000-0003-0532-1965

\section{Research Article}

\section{Keywords:}

Posted Date: December 6th, 2021

DOI: https://doi.org/10.21203/rs.3.rs-1123870/v1

License: (c) (1) This work is licensed under a Creative Commons Attribution 4.0 International License. Read Full License 


\section{Abstract \\ Objective.}

Obese patients have a higher prevalence of total hip arthroplasty (THA) and they are likely to experience a higher rate of pre-operative and post-operative complications. Pre-operative templating is a standard method of THA planning aiming to minimize the risk of complications. The accuracy of pre-operative templating depends on the knowledge of radiographic magnification factor. Whether and to what extent obesity affects radiographic magnification is not well described in literature. The purpose of this study was to determine whether obesity type affects hip radiographic magnification and quantify the relationship between the obesity measured and change in radiographic magnification.

\section{Materials and Methods.}

Digital radiographs of 303 patients who underwent THA were taken from clinical archives. The size of implanted femoral head was taken as an internal calibration marker to estimate hip radiographic magnification. Patients were stratified into obesity categories by body mass index (BMI). Patients' mass, $\mathrm{BMI}$, and body surface area (BSA) were studied as predictors of hip magnification.

\section{Results.}

There is a significant effect of obesity type on hip radiographic magnification (one-way ANOVA, $p<0.001$ ). The radiographic magnification correlates with patients' mass $(r=0.443, p<0.001), \mathrm{BMI}(r=0.450, p<0.001)$ and BSA $(r=0.443, p<0.001)$. For every $17 \mathrm{~kg}$ increase in patients' mass, $5 \mathrm{~kg} / \mathrm{m}^{2}$ increase in the BMl and for every $0.27 \mathrm{~m}^{2}$ in the BSA there is a 1 percent increase in the hip radiographic magnification. The increase in hip radiographic magnification with mass, BMI, and BSA is higher in females than in males.

\section{Conclusion.}

BMI could be used to estimate the increase in hip radiographic magnification due to obesity by adding $1 \%$ of magnification on average for each subsequent BMI category.

\section{Introduction}

Obesity is a rising global epidemic affecting over $10 \%$ of the adult population worldwide [1]. Excessive loading due to obesity is known to be associated with a wide range of degenerative musculoskeletal diseases, not least hip and knee osteoarthritis [2,3]. Thus, obese individuals have a substantially higher rate of joint arthroplasties than non-obese ones [4]. Patient obesity presents a complex challenge during total hip arthroplasty (THA) surgery [5] and it has a negative influence on the THA outcome [6]. The 
surgery time and subsequent short-term morbidity are higher in obese patients [7]. Obese patients are also at higher risk of THA instability [8], aseptic loosening and infection [4, 9].

Acetate or digital templating prior the surgery allows the surgeon to reduce surgery time [10] and choose the correct implant components to restore hip biomechanics [11]. It also reduces the risk of dislocation [12], femoral fractures or loosening [13] and leg length discrepancy [14]. Therefore, pre-operative templating in obese patients requires special consideration [15]. A prerequisite for pre-operative planning is an accurate correction of the radiographic magnification factor [16]. Radiographic magnification is a result of the divergence of the X-ray beam and it depends on the mutual position of the X-ray source, patient and detector (Fig. 1). It is reasonable to expect that patients with a higher amount of subcutaneous fat will have more distance between hip joint and detector, thereby higher magnification of radiograph (Fig. 1). The relation between body habitus and radiographic magnification has not been quantified yet. While some studies report weak dependence between the body mass index (BMI) and measured magnification $[16,17]$, others conclude that the effect of BMI on pre-operative planning accuracy is negligible $[18,19]$.

The primary aim of this study is to test the hypothesis that obesity type stratified by BMI affects hip radiographic magnification. The secondary aim is to quantify the relationship between patient body habitus and the increase in radiographic magnification. Parameters describing body habitus like mass (m) and body surface area (BSA) were tested as factors influencing hip magnification in addition to BMI.

\section{Patients And Methods}

The radiographs taken as a part of regular follow-ups were obtained from the records of patients who underwent hip arthroplasty from November 2012 to May 2016 at five clinics in the Czech Republic. All radiographs were exported from the hospital's picture archiving and communication systems in DICOM format and were anonymized prior to analysis. One randomly chosen hip was chosen in patients with bilateral hip arthroplasty. Patients' mass and height at the time of the follow-up were also obtained from patient records. Patients with incomplete records, e.g. missing mass at follow-up or poor quality of follow-up radiographs (motion artifacts, not clearly visible femoral head) were excluded from the study. The study includes 303 patients, 125 male and 178 female.

The magnification of radiographs $(M)$ was determined by comparing the prosthetic femoral head diameter in radiographs (measured by ImageJ [20]) with the implant real size, obtained from the operative notes. The measured size was compared with the real size of the prosthetic femoral head, obtained from the operative notes. The radiographic magnification $\mathrm{M}$ may differ at each clinic because of different radiological equipment and image handling as shown in the recent study [21]. To compare the global effect of obesity on the change in radiographic magnification, the data from each clinic were normalized relative to zero median. The difference from the median $(\Delta M)$ was used in further analysis. Analysis of original data for each clinic is provided as Supplementary files. 
Correlation between radiographic magnification and obesity was evaluated in all patients. In addition to the mass and the body mass index (BMI), it is frequent practice in medicine to estimate the human body surface area (BSA) [22]. BSA of patients was calculated using the Livingston \& Lee (2001) formula [23].

The patient's BMI was used to define obesity according to the WHO classification [1]. The 303 patients were stratified according to their BMI as follows: underweight <18.4 (2) normal; 18.5 to 24.9 (61); overweight, 25 to 29.9 (119); class-I obese, 30.0 to 34.9 (87); class-II obese, 35.0 to 39.9 (27) and class-III obese, 40.0 or higher (7). Underweight and class-III obese patients were excluded from ANOVA analysis because of the small sample size.

Statistical analysis was performed using R software (R Foundation for Statistical Computing, Vienna, Austria). Groups from different clinics were compared using a Student's t test for normally distributed data. The normality assumption was verified graphically. Correlation was calculated with the Pearson correlation coefficient; difference between two dependent correlations was analyzed using the Williams's test. Coefficients of linear regression are expressed as the mean and the standard error of the mean (SE). One-way analysis of variance (ANOVA) was performed to examine the effect of obesity category on radiographic magnification. The results were then further analysed with Tukey's post-hoc test. A $p$ value 0.05 was regarded as significant.

\section{Results}

The cohorts from different clinics are comparable in patients' mass, height, BMI, and BSA (t-test, $p=0.2)$. One-way between subject ANOVA was conducted to compare the effect of obesity type on the hip radiographic magnification for patients classified from normal weight to class-II obesity. Obesity has a significant effect on radiographic magnification $(F(3,290)=19.24, p<0.001)$. Post-hoc comparison using Tukey's HSD test indicated that the mean change in radiographic magnification is not significantly different between overweight and class-I obese patients ( $p=0.117$, Fig. 2). The difference between normal weight and overweight patients is on the border of significance $(p=0.031$, Fig. 2$)$.

The higher the mass, $\mathrm{BMI}$ or BSA, the higher the radiographic magnification (mass: $r=0.443,95 \%$ confidence interval $0.348-0.529$, BMI: $r=0.450,95 \%$ confidence interval $0.355-0.535$, BSA: $r=0.443$, $95 \%$ confidence interval $0.347-0.529$ ). Linear regression analysis demonstrates that for every $17 \mathrm{~kg}$ (SE $2.0 \mathrm{~kg}$ ) increase in patients' mass, $5 \mathrm{~kg} / \mathrm{m}^{2}\left(\mathrm{SE} 0.6 \mathrm{~kg} / \mathrm{m}^{2}\right)$ increase in the BMI (Fig. 3) or for every 0.27 $\mathrm{m}^{2}\left(\mathrm{SE} 0.032 \mathrm{~m}^{2}\right)$ in the BSA there is a 1 percent increase in the hip radiographic magnification. Correlation between the patients' mass, BMI, BSA and radiographic magnification is more obvious in females than in males (Tab. 1), this difference in correlation coefficients is statistically significant (Williams's test $p$ equals $0.008,0.046,0.002$ for mass, BMI and BSA). 1 percent increase in the hip radiographic magnification corresponds to increase in patients' mass, BMI and BSA for $19 \mathrm{~kg}$ (SE $4.7 \mathrm{~kg})$, 
$7 \mathrm{~kg} / \mathrm{m}^{2}\left(\mathrm{SE} 1.9 \mathrm{~kg} / \mathrm{m}^{2}\right)$, and $0.29 \mathrm{~m}^{2}\left(\mathrm{SE} 0.071 \mathrm{~m}^{2}\right)$ in males, respectively and $12 \mathrm{~kg}$ (SE $\left.1.2 \mathrm{~kg}\right), 4$ $\mathrm{kg} / \mathrm{m}^{2}\left(\mathrm{SE} 0.4 \mathrm{~kg} / \mathrm{m}^{2}\right)$, and $0.19 \mathrm{~m}^{2}\left(0.019 \mathrm{~m}^{2}\right)$ in females, respectively.

\section{Discussion}

Subcutaneous fat in obese patients increases the distance between the hip joint and the table during pelvis AP projection (Fig. 1). Therefore, the hip radiograph magnification should be considerably higher in obese patients. The present clinical study of 303 patients after total hip arthroplasty confirmed this assumption.

Similar results have been observed in the study of Archibeck et al. (2016) [24] who showed that BMI accounted for a significant amount of variability in the measured magnification both for internal and external marker. However, Boese et al. (2015) [17] and The et al. (2007) [16] observed weak correlation between hip radiographic magnification and BMI. Study using a double marker method by King et al. (2009) [25] also showed a weak correlation between BMI and magnification. The weak correlation observed in previous studies, could be explained by factors others than obesity that influence magnification. These effects are shown as data scattering in Fig. 3 and may be attributed to interindividual variation between the patients. The data presented within this study are based on cohort taken from homogenous population in the Czech Republic where $95 \%$ of the population are Caucasians. It has been shown that body habitus also depends on race [26] and we may expect a weaker correlation in a non homogenous population. The observed correlation is also affected by the range of studied BMl, e.g. no difference could be found when comparing magnification in normal and overweight patients (Fig. 2).

The secondary aim of the study was to quantify to what extent obesity affects patient's radiographic magnification. Patients' mass, BMI and BSA are approximately at the same level of significance when predicting hip radiographic magnification (Tab. 1). Calculation of BSA is not straightforward, and discrepancies between the most of the known BSA formulae can reach $0.5 \mathrm{~m}^{2}$ for normal patient [27]. Therefore we do not recommend using BSA for magnification error estimation.

Descamps et al. (2010) [28] report that the change in radiographic magnification depends on patient's mass linearly with the proportionality constant 0.07 . We have observed that for 1 percent increase in magnification, there is a $17 \mathrm{~kg}$ increase in patient's mass on average. It corresponds to proportionality constant of 0.06, which is in agreement with the results of Descamps et al. (2010) [28]. We further observed that for every percent increase in magnification, there is $5 \mathrm{~kg} / \mathrm{m}^{2}$ increase in BMI (Fig. 3). The value of $5 \mathrm{~kg} / \mathrm{m}^{2}$ corresponds with the range of each obesity type by WHO (2000) [1] and it follows that there is roughly 1 percent difference in radiographic magnification between obesity types (Fig. 2). More precisely, the radiographic magnification between obesity types (difference $5 \mathrm{~kg} / \mathrm{m}^{2}$ in BMl) increases for $0.7 \%$ and $1.2 \%$ for male and female, respectively. The correction for magnification is higher and more reliable in females than in males (Tab. 1) as females are likely to have higher accumulation of adipose tissue in the gluteo-femoral area [29]. 
Our study has some limitations. The height and weight were acquired retrospectively from clinical records. Prospective data acquisition might be more reliable. The study cohort contains a limited number of morbidly obese and underweight patients and further study is required to quantify the effect of obesity on radiographic magnification in these patients. The method based on implanted femoral head as an internal magnification marker is adopted as a gold standard in measuring hip radiographic magnification [17]. Within this method, the change in magnification due to lateral shift is neglected. Analysis of Caucasian patients is presented in the current study. It potentially limits the generalizability of results to patients of African or Asian origin with different adipose tissue distribution [29]. Obesity also affects image quality in radiography due to decreased penetration and attenuation through subcutaneous fat [30]. Increased exposure factors requiring elongated exposure time results in motion artefacts [31]. Therefore, the lower quality of radiographs in obese patients is a potential source of error in radiographic magnification estimation.

The clinically tolerable margin of magnification error depends on the steps between implant sizes. Franken et al. (2010) [18] showed, that to template exactly for a specific implant size, the magnification error should be less than 2 percent for the ABG-II implant series. Our study shows that the change in radiographic magnification for class-I obese and class-ll obese with respect to normal-weight patients is outside the limit proposed by Franken et al. (2010) [18]. Pre-operative radiographs performed with a magnification marker at the greater trochanter level could improve accuracy of hip templating in obese patients [32]. However, placing the magnification marker in obese patients could be difficult as the marker projected image could be outside of the captured field [33]. Some studies even propose to use fixed magnification factor instead of the magnification marker method $[24,18]$. The fixed magnification estimation could be improved by considering the patient's BMI.

\section{Conclusions}

Knowledge of the exact dimensions of bone structure plays a key role in pre-operative planning. If the magnification marker method is not applicable, BMI could be used to estimate the increase in hip radiographic magnification due to obesity.

\section{Declarations}

\section{Ethical approval}

The study was approved by the Ethics Committee of the Faculty of Biomedical Engineering, Czech Technical University in Prague, Czech Republic. The study was conducted in accordance with the Helsinki Declaration.

Consent for publication

Not applicable 
Availability of data and materials

The datasets analysed during the current study are available from the corresponding author on reasonable request.

Competing interest

The authors declare that they have no conflict of interest.

Funding

This work was supported by Czech Health Research Council, Project No. NU21-06-00084 (authors: MD PF JH); and student grant project University Palacký, Project No. IGA_LF UPOL_2017_021 (author: JG).

Authors' contributions

Jana Hornová Ph.D.. - interpretation of data

Maroš Hrubina MD, Ph.D. - data acquisition

Eduard Štastný MD, Ph.D. - data acquisition

Andrea Košková MD - data acquisition

Petr Fulín MD, Ph.D. - data acquisition and analysis

Jiří Gallo prof., MD, Ph.D. - data acquisition and analysis

David Pokorný, MD, Ph.D. - drafted the work and revised it

Matej Daniel M.Sc., Ph.D. - the conception and design of the work, data analysis

Acknowledgment

We thank lan Wiebkin for comments that greatly improved the manuscript.

\section{References}

1. Obesity: preventing and managing the global epidemic. Report of a WHO consultation. World Health Organ Tech Rep Ser. 2000;894:i-xii, 1-253.

2. Meng H, O'Connor DP, Lee BC, Layne CS, Gorniak SL. Alterations in over-ground walking patterns in obese and overweight adults. Gait Posture. 2017 Mar; 53:145-150.

3. Wen L, Kang JH, Yim YR, Kim JE, Lee JW, Lee KE, Park DJ, Kim TJ, Park YW, Kweon SS, Lee YH, Yun YW, Shin MH, Lee SS. Associations between body composition measurements of obesity and 
radiographic osteoarthritis in older adults: Data from the Dong-gu Study. BMC Musculoskelet Disord. 2016 Apr 29;17:192.

4. Haynes J, Nam D, Barrack RL.. Obesity in total hip arthroplasty: does it make a difference? Bone Joint J. 2017 Jan;99-B(1 Supple A):31-36.

5. Russo MW, Macdonell JR, Paulus MC, Keller JM, Zawadsky MW. Increased Complications in Obese Patients Undergoing Direct Anterior Total Hip Arthroplasty. J Arthroplasty. 2015 Aug;30(8):1384-7.

6. Haverkamp D, Klinkenbijl MN, Somford MP, Albers GH, van der Vis HM. Obesity in total hip arthroplasty-does it really matter? A meta-analysis. Acta Orthop. 2011 Aug;82(4):417-22.

7. Duchman KR, Pugely AJ, Martin CT, Gao Y, Bedard NA, Callaghan JJ. Operative Time Affects ShortTerm Complications in Total Joint Arthroplasty. J Arthroplasty. 2017 Apr;32(4):1285-1291.

8. Elkins JM, Daniel M, Pedersen DR, Singh B, Yack HJ, Callaghan JJ, Brown TD. Morbid obesity may increase dislocation in total hip patients: a biomechanical analysis. Clin Orthop Relat Res., 2013 Mar;471(3):971-80.

9. Wu ES, Cherian JJ, Jauregui JJ, Robinson K, Harwin SF, Mont MA. Patient-Reported Outcomes Following Total Hip Arthroplasty Stratified by Body Mass Index. Orthopedics. 2016 May 1;39(3):e5727.

10. Crutcher JP. Pre-operative Planning for Total Hip Arthroplasty. Oper Tech Orthop. 2000; 2 (2): 102105.

11. Scheerlinck T. Primary hip arthroplasty templating on standard radiographs. A stepwise approach. Acta Orthop Belg. 2010 Aug;76(4):432-42.

12. Gupta A, Redmond JM, Hammarstedt JE, Petrakos AE, Vemula SP, Domb BG. Does Robotic-Assisted Computer Navigation Affect Acetabular Cup Positioning in Total Hip Arthroplasty in the Obese Patient? A Comparison Study. J Arthroplasty. 2015 Dec;30(12):2204-7.

13. Heinert G, Hendricks J, Loeffler MD. Digital templating in hip replacement with and without radiological markers. J Bone Joint Surg Br., 2009 Apr;91(4):459-62.

14. Petretta R, Strelzow J, Ohly NE, Misur P, Masri BA. Acetate templating on digital images is more accurate than computer-based templating for total hip arthroplasty. Clin Orthop Relat Res. 2015 Dec;473(12):3752-9.

15. Abir F, Bell R. Assessment and management of the obese patient. Crit Care Med. 2004 Apr;32(4 Suppl):S87-91

16. The B, Kootstra JW, Hosman AH, Verdonschot N, Gerritsma CL, Diercks RL. Comparison of techniques for correction of magnification of pelvic X-rays for hip surgery planning. J Digit Imaging. 2007 Dec;20(4):329-35.

17. Boese CK, Lechler P, Rose L, Dargel J, Oppermann J, Eysel P, Geiges H, Bredow J. Calibration Markers for Digital Templating in Total Hip Arthroplasty. PLoS One. 2015 Jul 13;10(7):e0128529.

18. Franken M, Grimm B, Heyligers I. A comparison of four systems for calibration when templating for total hip replacement with digital radiography. J Bone Joint Surg Br. 2010 Jan;92(1):136-41. 
19. Pourmoghaddam A, Dettmer M, Freedhand AM, Domingues BC, Kreuzer SW. A patient-specific predictive model increases pre-operative templating accuracy in hip arthroplasty. J Arthroplasty. 2015 Apr;30(4):622-6.

20. Schneider CA, Rasband WS, Eliceiri KW. NIH Image to ImageJ: 25 years of image analysis. Nat Methods. 2012 Jul;9(7):671-5.

21. Hornová J, Růžička P, Hrubina M, Štłastný E, Košková A, Fulín P, Gallo J, Daniel M. Magnification of digital hip radiographs differs between clinical workplaces. PLoS One. 2017 Nov 30;12(11):e0188743.

22. Verbraecken J, Van de Heyning P, De Backer W, Van Gaal L. Body surface area in normal-weight, overweight, and obese adults. A comparison study. Metabolism. 2006 Apr;55(4):515-24.

23. Livingston $\mathrm{EH}$, Lee S. Body surface area prediction in normal-weight and obese patients. Am J Physiol Endocrinol Metab. 2001 Sep;281(3):E586-91.

24. Archibeck MJ, Cummins T, Tripuraneni KR, Carothers JT, Murray-Krezan C, Hattab M, White RE Jr. Inaccuracies in the Use of Magnification Markers in Digital Hip Radiographs. Clin Orthop Relat Res. 2016 Aug;474(8):1812-7.

25. King RJ, Makrides P, Gill JA, Karthikeyan S, Krikler SJ, Griffin DR. A novel method of accurately calculating the radiological magnification of the hip. J Bone Joint Surg Br. 2009 Sep;91(9):1217-22.

26. Demerath EW, Sun SS, Rogers N, Lee M, Reed D, Choh AC, Couch W, Czerwinski SA, Chumlea WC, Siervogel RM, Towne B. Anatomical patterning of visceral adipose tissue: race, sex, and age variation. Obesity (Silver Spring). 2007 Dec;15(12):2984-93.

27. Redlarski G, Palkowski A, Krawczuk M. Body surface area formulae: an alarming ambiguity. Sci Rep. 2016 Jun 21;6:27966.

28. Descamps S, Livesey C, Learmonth ID. Determination of digitised radiograph magnification factors for pre-operative templating in hip prosthesis surgery. Skeletal Radiol. 2010 Mar;39(3):273-7.

29. Karastergiou K, Smith SR, Greenberg AS, Fried SK. Sex differences in human adipose tissues - the biology of pear shape. Biol Sex Differ. 2012 May 31;3(1):13.

30. Woods AL, Miller PK, Sloane C. Patient obesity and the practical experience of the plain radiography professional: On everyday ethics, patient positioning and infelicitous equipment. Radiography. 2016 May; 22 (2): 118-123.

31. Yanch JC, Behrman RH, Hendricks MJ, McCall JH. Increased radiation dose to overweight and obese patients from radiographic examinations. Radiology. 2009 Jul;252(1):128-39.

32. Sershon RA, Diaz A, Bohl DD, Levine BR. Effect of Body Mass Index on Digital Templating for Total Hip Arthroplasty. J Arthroplasty. 2017 Mar;32(3):1024-1026.

33. Wimsey S, Pickard R, Shaw G. Accurate scaling of digital radiographs of the pelvis. A prospective trial of two methods. J Bone Joint Surg Br. 2006 Nov;88(11):1508-12.

\section{Tables}




\begin{tabular}{lrl}
\hline \multicolumn{3}{l}{ ParameterMale FemaleTotal } \\
\hline mass & 0.3510 .592 & 0.443 \\
\hline BMI & 0.3520 .539 & 0.450 \\
\hline BSA & 0.3000 .587 & 0.443 \\
\hline
\end{tabular}

Table 1: Pearson correlation coefficient between the patients' parameter and the change in radiographic magnification $\Delta \mathrm{M}$. All correlations are statistically significant $(\mathrm{p}<0.001)$.

\section{Figures}

\section{X-ray source}
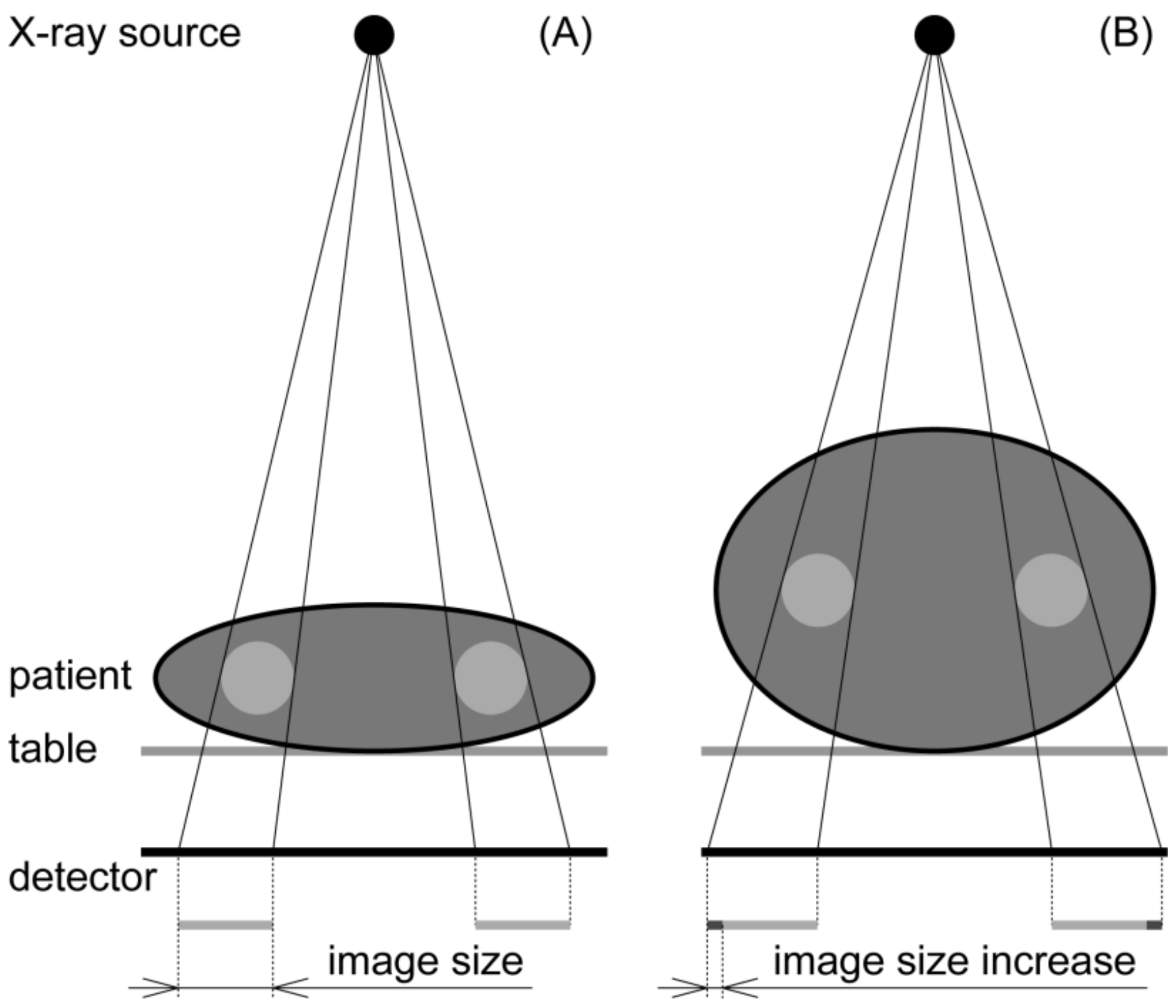
Figure 1

Radiographic magnification in (A) a normal and (B) an obese patient. Owing to the higher position of the hip above the table in the obese patient (B), the image size of the femoral head is larger than in a normal patient (A).

\section{Figure 2}

Boxplot interaction between hip radiographic magnification and obesity. The vertical axis shows the difference from median magnification determined at each hospital $\Delta M$. The horizontal axis shows the obesity category classified by BMI (p reported from Tukey's post-hoc test).

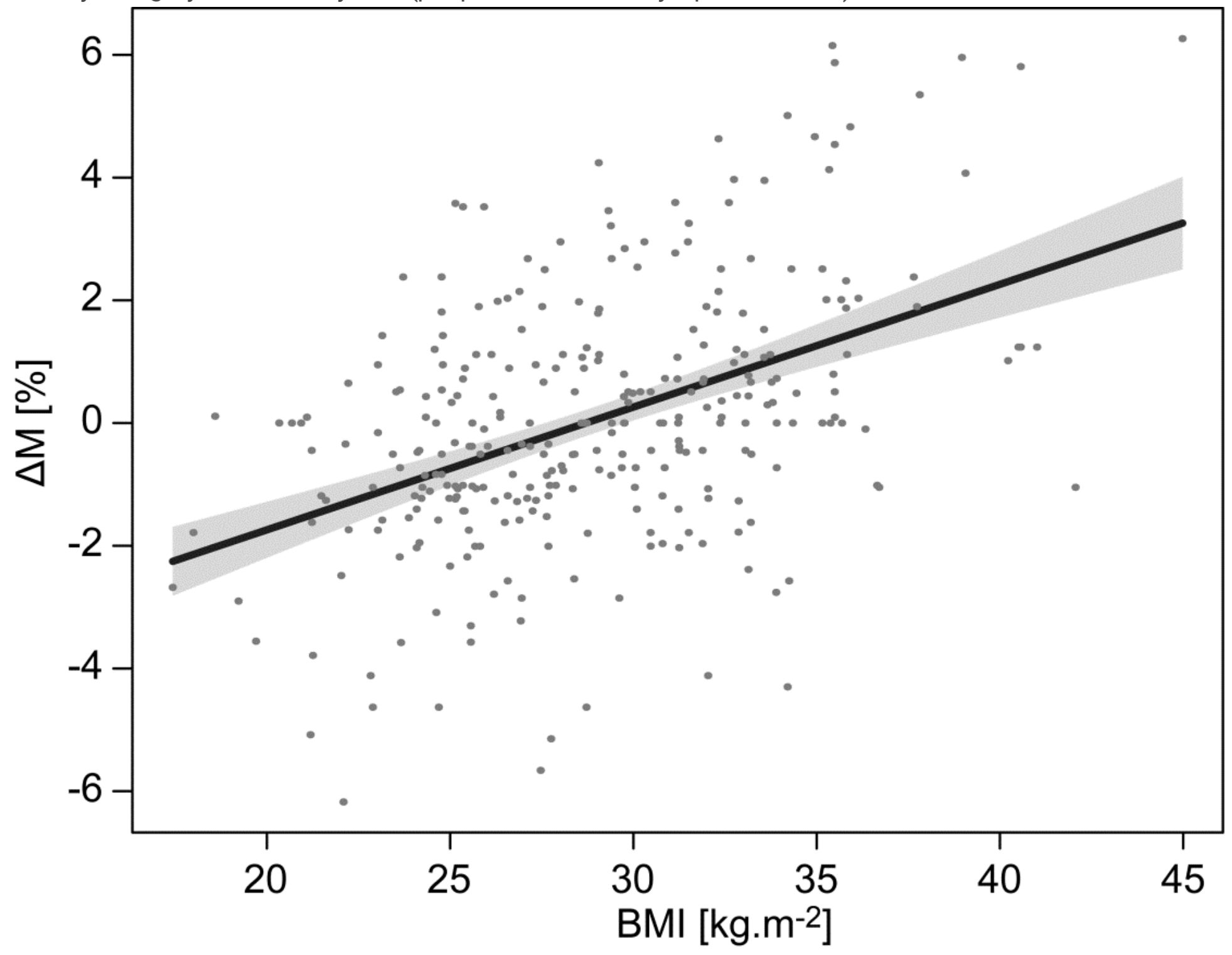

Figure 3

Relationship between patients' BMI and change in hip radiographic magnification $\Delta \mathrm{M}$. The solid black line represents the linear regression; the shaded gray area denotes the $95 \%$ confidence intervals. 


\section{Supplementary Files}

This is a list of supplementary files associated with this preprint. Click to download.

- Supplementarymaterialv2.docx 